\title{
The Impact of Group Cognitive Complexity on Group Satisfaction: A Person-Environment Fit Perspective
}

\author{
Bradley W. Mayer \\ Lamar University \\ Kathleen Dale \\ Minnesota State University, Mankato
}

\begin{abstract}
Groups have the potential to increase the satisfaction of their members (Campion, Medsker, \& Higgs, 1993; Gladstein, 1984; Hackman, 1987; Katzell \& Guzzo, 1983; Mason \& Griffin, 2002, 2003). Thus, consideration of group characteristics in organizations is an important issue (Druckman \& Bjork, 1991). In this study, the interactive influence of group cognitive complexity, task complexity, and group structure with satisfaction was analyzed. The findings suggest that when a task is complex, a decentralized structure leads to greater satisfaction than a centralized structure. Furthermore, groups lower in cognitive complexity were influenced more than complex groups by a mismatch between task complexity and group structure.
\end{abstract}

Key Words: cognitive complexity, group structure, task complexity, group characteristics

\section{Introduction}

Research using decision making groups indicates that many informational, short-term, and long-term memory limitations of individuals can be alleviated by having a group perform tasks (Cooke et al., 2003; Devine, 2002; Lord \& Foti, 1986; Weber \& Donahue, 2001). This improved cognitive capacity is a function of cognitive complexity. Cognitive complexity is defined as the degree to which a person within a particular domain utilizes multiple perspectives when perceiving and evaluating stimuli (Kelly, 1955; Goodwin \& Ziegler, 1998; Curseu \& Rus, 2005). These multiple perspectives can be referred to as dimensions that represent the grouping or ordering of stimuli (Streufert \& Swezey, 1986). Researchers suggest that the ability to differentiate between various alternatives and on many dimensions could influence the actions of individuals and help them become better strategic planners, problem solvers, and decision makers (Hodgkinson, 2002; McNamara, Luce, \& Tompson, 2002; Neill \& Rose, 2006; Streufert, 1984; Streufert et al., 1965; Streufert, Kliger, Castore, \& Driver, 1967; Streufert \& Swezey, 1986).

Because groups are able to perform tasks, it is assumed that they possess cognitive 
abilities and are able to acquire knowledge and process information similarly to individuals (Campbell, 1974). Groups are entities that collectively possess motivational states and cognitive processes (Bartel \& Saavedra, 2000; Park, Baker, \& Lee, 2008). It is our intent, therefore, to focus on the aggregation of individual cognitive complexity-the collective mind of group members (Weick \& Roberts, 1993).

Groups have the potential for simultaneously increasing both the performance and the satisfaction of their members (Campion, Medsker, \& Higgs, 1993; Gladstein, 1984; Hackman, 1987; Katzell \& Guzzo, 1983; Mason \& Griffin, 2002, 2003); thus, consideration of group characteristics in organizations is an important issue (Druckman \& Bjork, 1991). A key consideration when forming groups is the capacity for the group members to process information related to the task performed. Cognitive complexity enhances an individual's ability to process information and interpret and understand one's surroundings (Blaylock \& Rees, 1984; Bieri, 1956). Groups, having similar abilities as individuals, also should benefit from higher levels of cognitive complexity. As a result, managers may find it worth their time to take group level cognitive complexity into account when designing work groups.

Previous research suggests that environmental characteristics are also key for effective group functioning. McGrath (1984) reviewed group research and concluded that the type of task and group structure is of major importance in measuring group satisfaction and effectiveness. Furthermore, the type of task and group structure is likely to influence the cognitive processes of groups (Ashforth \& Fried, 1988; Lord \& Kernan, 1987; Louis \& Sutton, 1991), such that the variation in structural make-up and complexity of a task may require differing cognitive capabilities. These considerations have led us to the development of three research questions: (1) Does a relationship exist between task complexity, group cognitive complexity, and the satisfaction of the group? (2) Does a relationship exist between group structure, group cognitive complexity, and the satisfaction of the group? (3) Does group cognitive complexity, group structure, and task complexity interact to influence the satisfaction of the group? In the following sections, definitions, past research, and hypotheses for the interactive effects of task complexity, group structure, and group cognitive complexity on satisfaction are presented.

\section{Implications of Context for Group Level Cognitive Complexity}

Research on individual behavior is filled with inconsistent findings that have led researchers to suggest that one's interaction with his or her context may influence behavior, what some have called person-environment fit (Manz, 1992; Manz, Mossholder, \& Luthans, 1987). For example, considerable research suggests that some individuals prefer complex settings and novel or stimulating environments while others prefer calm settings (Day, 1966; 1967; 1968; Jones, 1964; Minton, 1963). These inconsistent findings may be explained, in part, by the failure to examine cognitive 
complexity in combination with environmental variables and their influence on group outcomes.

We propose that cognitive complexity should be considered within the framework of person-environment fit given the variation in decision-making and contextual characteristics encountered by individuals and groups in organizations. Personenvironment fit is defined as the degree to which an individual's characteristics harmonize with those of his or her environment (Spokane, 1996). In work situations, higher degrees of fit predict positive work outcomes (Hoffman \& Woehr, 2006; KristofBrown, Zimmerman \& Johnson, 2005; Tinsley, 2000; Vogel \& Feldman, 2009). Thus, we propose that including cognitive complexity in the person-environment fit equation may be the key to understanding the inconsistent findings in relationships between both task complexity and group structure with valued group outcomes such as satisfaction.

\section{Task Complexity and Cognitive Complexity}

According to Wood (1986), task complexity can be defined as a function of three dimensions of the task itself: number of distinct components and informational cues necessary for completion of the task, complication on the patterns of relationships among informational cues, and stability of those patterns over time. Thus, task complexity may be evaluated by assessing the number of distinguishable and dissimilar alternatives present and uniqueness of the task to the participants (Berlyne, 1960; Scott \& Erskine, 1980).

Researchers have found that certain combinations of tasks and decision styles will be more effective for group performance (Cheng \& Chang, 2009; DeLuca \& Stumpf, 1981; Curseu, Schruijer \& Boros, 2007; Schroder, Driver, \& Streufert, 1967). For example, individuals with high cognitive complexity experience a task differently than do those with lower cognitive complexity because they are better equipped to tolerate ambiguity, resolve conflicts, use feedback cues, and vary their decision-making strategies (e.g., Schroder \& Suedfeld, 1971; Streufert \& Streufert, 1978; Wood, 1986). Thus, when confronted with complex issues, groups comprised of individuals higher in cognitive complexity should feel more comfortable with divergent ways of understanding problems, effectively introduce conflict into their decision-making (Bartunek, Gordon, \& Weathersby, 1983), and have better coverage of the topic, leading to greater satisfaction with the process than groups lower in cognitive complexity.

Inconsistencies in the research on cognitive complexity and satisfaction exist. While some researchers found no evidence of a relationship between cognitive complexity and job satisfaction (Streufert, Pogashi, \&Piasecki, 1988), others found that cognitively complex individuals have lower job satisfaction than less complex individuals (Goodwin, Wofford, \& Harrison, 1990). A potential explanation for these 
inconsistencies may be an issue of matching cognitive complexity to task complexity. Schruijer \& Vansina (1997) found that the variety of knowledge (cognitive complexity) group members have should be relevant for the task. This finding is supported by metaanalysis research (Bower, Pharmer, \& Salas, 2000). A fit between cognitive complexity and task complexity may reduce the frustration that could arise when cognitively complex individuals perform tasks that do not require the use of their informationprocessing ability, or when less complex individuals perform tasks that require the use of an ability that they do not have.

Activation level (boredom) provides additional insight into appropriate levels of task complexity for group satisfaction. According to Fisher (1987), boredom may be caused by both qualitative underload (tasks that are simple, repetitive, and have low mental demands) as well as qualitative overload (tasks that are not understood or regarded as too difficult). These variations in task complexity influence the affective, cognitive, physiological, and behavioral responses of workers (Simonson \& Weiser, 1976). Activation theory describes the basis for this influence (Fiske \& Maddi, 1961; Gardner, 1986; Gardner \& Cummings, 1988; Huber, 1985; Scott, 1966). According to activation theory, it is not enough just to consider the stimulation of the task; rather, a person's preference or values for different content must be considered. Thus, a match between the situation and what the person can handle should relieve boredom (Fisher, 1987). Likewise, a match between task complexity (the situation) and cognitive complexity (what the person can handle) should relieve boredom and influence attitudes such as satisfaction. Thus, the following hypothesis is proposed:

Hypothesis 1: Group cognitive complexity and task complexity will interact and be related positively to job satisfaction.

\section{Group Structure and Cognitive Complexity}

Group structure refers to the location of decision-making authority in the group. In a centralized structure, the concentration of decision-making authority rests with a central position (formal leadership) and most communication flows through that central position (Shaw, 1964). In a decentralized structure, decision-making authority rests with all members of the group and communication flows in all directions and to all group members (Shaw, 1964).

Early research has mixed findings concerning group structure and satisfaction. Some researchers have found that individuals receive greater satisfaction from decentralized groups that have active participation (Cummings, Huber, \&Arendt, 1974; Greenberg \& Folger, 1983; Miller \& Monge, 1986). Others suggest that decentralized groups may suffer from poor coordination of information, resulting in poor production and lower satisfaction (Borsig \& Frey, 1979). To the extent that a centralized group structure facilitates discussion and enhances the likelihood of a superior decision, subjects may 
feel more satisfied.

Group cognitive complexity may be a factor in the inconsistent results discussed above. Streufert and Swezey (1986) propose that optimal group functioning is more likely to occur when group structure is matched with the cognitive complexity of group members. In a decentralized group structure, decision-making is likely to require extensive discussion and argument. Because groups with high cognitive complexity will have more developed information processing abilities, more adept use of conflict in problemsolving situations, and a higher tolerance of stress and ambiguity (Fiske \& Taylor, 1984), these groups may be more successful with decentralized structures. These groups are more apt to use an integrative approach to decision-making (Rose, Mason, \& Dicken, 1987) which leads to greater satisfaction (Wall \& Nolan, 1987). Further, groups with higher cognitive complexity may require a decentralized structure in order to reach optimal levels of activation and communication. In contrast, groups with low cognitive complexity and a decentralized structure may suffer from poor coordination of information and ultimately extreme conflict and low activation. Groups with lower cognitive complexity may be more likely to excel in a centralized structure since they are less proficient at taking the perspective of others (Triandis, 1977).

Thus, a group higher in cognitive complexity should experience greater satisfaction in a decentralized group structure than a group with lower cognitive complexity.

Furthermore, high cognitive complexity should help group members handle greater limits of conflict; make better use of information processing; and be self-directing, selfmotivating, and flexible in their group processes (Fiske \& Taylor, 1984), all of which are important considerations to satisfaction in a decentralized group structure. Thus, the following hypothesis is proposed:

Hypothesis 2: Cognitive complexity and decentralization of group structure will interact and be related positively to satisfaction.

\section{Task Complexity and Group Structure}

Research suggests that decentralized structures outperform centralized structures when more complex tasks are being carried out (Carroll \& Burton, 2000; Shaw, 1954). As task complexity increases, the need for a decentralized group structure becomes more important for group satisfaction (Campbell \& Gingrich, 1986; Greenberg \& Folger, 1983; Miller \& Monge, 1986). Conversely, for groups performing less complex tasks that require very little need for collaboration with others, a centralized structure will suffice (Brown \& Miller, 2000; Galbraith, 1977; March \& Simon, 1958). Thus, the following hypothesis is proposed:

Hypothesis 3: Group structure and task complexity will interact to affect satisfaction such that a complex task being performed in a decentralized group structure will be 
related positively to satisfaction.

Task Complexity, Group Structure, and Cognitive Complexity

Higher task complexity may require more discussion and communication among group members in order to investigate the various alternatives available. This would suggest that a decentralized structure facilitates the sharing of ideas among group members. Higher group cognitive complexity enhances the ability to tolerate ambiguity, resolve conflicts, use feedback cues, and vary decision-making styles (Duncan, 1973; Galbraith, 1969; Pennings, 1975; Schroder \& Suedfeld, 1971; Streufert \& Streufert, 1978; Wood, 1986). As discussed earlier, the activation level for group members is influenced by the task complexity and group structure. Within the context of high task complexity and a decentralized structure, activation will be optimal for groups with high cognitive complexity. Groups with low cognitive complexity should have optimal activation given a simple task within a centralized group structure. Thus, the following hypothesis is proposed:

Hypothesis 4: Cognitive complexity, decentralized group structure, and task complexity will interact and be related positively to job satisfaction.

\section{Method}

\section{Sample}

A sample of 228 business students at a mid-size Southwestern University participated in the experiment for course credit. Participants were placed in 76 three-person groups. In order to ensure an appropriate level of statistical power for the study, the required sample size was determined using Cohen and Cohen's (1983) power analysis procedure. The power analysis indicated that the sample size should be 80 groups in order to obtain a medium effect size, with a two-tailed alpha of .05 and a target power of .70. After eliminating certain groups because of blank responses, 76 triads remained for a total of 228 subjects. The average age of the participants was 23.7 years; $47 \%$ were males and $53 \%$ were females.

\section{Design}

A $2 \times 2 \times 2$ factorial design was used, with two levels of task complexity (complex; noncomplex) and two levels of group structure (centralized; decentralized) blocked on group cognitive complexity (high; low). This resulted in eight treatment conditions consisting of all possible combinations of the three independent variables.

\section{Experimental Task}


The problem-solving task used was Johnson and Johnson's (1994) Winter Survival Exercise. It is a single trial decision-making task that was conducted without information feedback or time pressure. The Winter Survival Exercise has been identified as a task that is similar to the types of problems faced by managers (Bottger \& Yetton, 1987).

Participants were given a scenario describing the crash of an airplane in a remote area of upper Minnesota during the winter. Each participant was supplied with a list of items and was asked to independently rank the items according to importance for survival. Following the individual rankings, the members of the group were instructed to collectively rank each of the survival items and write explanations for the use of each item in their struggles for survival.

The Winter Survival Exercise was selected because it represents an opportunity to manipulate both task complexity and group structure. First, task complexity can be easily manipulated by varying the number of items the groups are given to rank order according to their importance for survival. This manipulation is consistent with Wood's (1986) definition of task complexity. Second, group structure can be easily manipulated as either centralized or decentralized based on the instructions given to the groups by the experimenter.

\section{Independent Variable Measures and Manipulations}

The three independent variables in this study were group cognitive complexity, task complexity, and group structure. The measures and manipulations for these variables are discussed below.

\section{Group Cognitive Complexity}

Group cognitive complexity was measured using the Repertory Grid technique. This measure was developed by Kelly (1955) and later modified by Bieri (1961). The Repertory Grid technique was selected for measuring cognitive complexity because the reliability and construct validity of this tool has been well established (Tripodi \& Bieri, 1964; Vannoy, 1965). Cognitive complexity is assessed using the Repertory Grid by measuring the ability of a person to differentiate among various elements. A person utilizing a greater number of constructs to interpret others' behaviors is scored as more cognitively complex than those relying on only a few constructs.

Before participation in the experiment, subjects responded to a modified version of the Repertory Grid test (Bieri, 1961) to measure their cognitive complexity. Low scores on the Repertory Grid exercise indicate high cognitive complexity while high scores indicate low cognitive complexity. The level of group cognitive complexity is assessed by aggregating the cognitive complexity scores of the group members (Cooke, Salas, 
Cannon-Bowers, \& Stout, 2000; Cooke, Salas, Kiekel, \& Bell, 2004; Dunn \& Ginsberg, 1986; Ginsberg, 1990; Lagan-Fox, Code, \& Langfield-Smith, 2000; Mohammed, Klimoski, \& Rentsch, 2000).

Groups with different cognitive complexity profiles were created prior to the experiment, based on the individuals' cognitive complexity scores. High cognitive complexity groups were created by placing individuals with scores below the median (48) in groups (low scores equal high cognitive complexity), and low cognitive complexity groups were created by placing individuals with scores above the median into groups. The cognitive complexity score of each of the group members was averaged to develop a measure of the group's cognitive complexity (Walsh, Henderson, \& Deighton, 1988). The minimum group cognitive complexity score was 39 and the maximum was 60 , with an average group score of $47.38(S D=4.67)$.

\section{$\underline{\text { Task Complexity }}$}

Task complexity was manipulated according to the number of survival items available for consideration on the Winter Survival Exercise. In the high task complexity condition, the experimenter provided a list of 15 survival items. These 15 items included a ball of steel wool, newspapers, a compass, a hand ax, a cigarette lighter, a 45-caliber pistol, a sectional air map, canvas, a shirt and pants, shortening, whiskey, chocolate bars, a knife, ski poles, and gauze. In the low task complexity condition, the experimenter provided a list of eight items which were randomly selected from the 15-item list by drawing item names from a container. The 8-item list included a ball of steel wool, newspapers, a cigarette lighter, a 45-caliber pistol, chocolate bars, a shirt and pants, and a hand ax.

\section{Group Structure}

Group structure was manipulated by instructions from the experimenter. The instructions given to the groups with the decentralized group structure (i.e., without a leader) were as follows (Johnson \& Johnson, 1994):

This is an exercise in group decision-making. Your group is to employ the method of group consensus in reaching its decision. This means that the ranking for each of the fifteen (eight for simplified version) survival items must be agreed upon by all group members before it becomes a part of the group decision. Consensus is difficult to reach. Therefore, not every ranking will meet with everyone's complete approval. Try, as a group, to make each ranking one with which all group members can at least partially agree.

Members in these groups were seated in strategic positions where all three members 
had equal space between them, and there was no implication of an assigned leadership position. This was done to enhance the flow of communication in all directions.

The instructions for the groups with a centralized group structure (i.e., the group had a specified group leader) were as follows (Johnson \& Johnson, 1994):

Your group is to discuss what the rankings of the survival items should be. At the end of the decision-making process, the group's leader will hand in the group's best ranking of the items. The role of the group members is to provide as much help as the leader wants in trying to determine how the items should be ranked. The leader in this group is responsible for making the final decision.

These groups were seated so that the leader was 10 feet away from the two other members. The centralized structure was further imposed on these groups by instructing the leader that he or she was allowed to only speak with one member at a time. The other two members were approximately ten feet apart and were not allowed to communicate with each other, nor could they hear the other's conversation with the leader. A physical barrier placed between the two members facing the leader of the group emphasized this separation.

\section{Dependent Measure}

Satisfaction was measured using a 20 -item semantic differential scale developed by Stone (1977). This scale was selected for measuring satisfaction because of its focus on task characteristics. Ten of the 20 items constituted the satisfaction scale. The remaining items were distracters and were not used in the analyses. Individual satisfaction scores were determined by adding ratings across the ten items. A group satisfaction score was calculated by averaging the three individual satisfaction scores $(\alpha=.86)$.

\section{Procedure}

In Phase I of the study, the Repertory Grid (Bieri, 1961; Kelly, 1955) was used to measure the cognitive complexity of each subject. Once the cognitive complexity scores were obtained from the subjects, they were placed into groups of three based on their complexity scores. The groups were homogenous in that all three group members were either high in cognitive complexity or else all three group members were low in cognitive complexity.

In Phase II, the task complexity and group structure conditions were assigned to the groups. This resulted in eight experimental groups. When the subjects reported to the 
laboratory, they were given a packet of materials containing four copies of the Winter Survival Exercise (one for each individual and one for the group), a score sheet, and procedural instructions. The participants were instructed first to complete the decision form individually so that the results indicated their own decisions.

The instructions explained that the group task was the same as the individual task and that the group goal was to determine one best solution that was as close as possible to the solution of the winter survival experts. Furthermore, to facilitate individual and group motivation, groups were told that they would find out how their group solutions compared with the experts' solutions. The task was reviewed with the participants, emphasizing that their survival depended upon the quality of their decision.

The decentralized groups were instructed to communicate with one another and determine the rankings of the survival items by group consensus. To enhance group consensus, specific instructions were given to the groups to eliminate conflict-reducing procedures. In contrast, the groups with a leader were simply given the instructions that set up the centralized group structure as described previously (Johnson \& Johnson, 1994).

Once the experiment was completed, participants were given a post-task questionnaire to obtain demographic data and manipulation checks. Then they were given the experts' rankings of each item in the Winter Survival Exercise with the rationale for each, were debriefed, and were thanked for their participation.

\section{Results}

Descriptive statistics, correlations, and internal consistency reliabilities for all measures are presented in Table 1. Means, standard deviations, and sample size by condition for each independent variable are presented in Table 2.

Table 1. Descriptive Statistics, Correlations, and Internal Consistency Reliabilities

\begin{tabular}{|c|c|c|c|c|}
\hline Variables & Mean & $\begin{array}{c}\text { Standard } \\
\text { Deviation }\end{array}$ & $\begin{array}{c}\text { Group } \\
\text { Cognitive } \\
\text { Complexity }\end{array}$ & $\begin{array}{c}\text { Satisfaction } \\
\text { Scale }\end{array}$ \\
\hline $\begin{array}{c}\text { Group } \\
\text { Cognitive } \\
\text { Complexity }\end{array}$ & 47.38 & 4.67 & .73 & - \\
\hline $\begin{array}{c}\text { Satisfaction } \\
\text { Scale }\end{array}$ & 20.55 & 2.66 & ${ }^{*}-0.16$ & .83 \\
\hline
\end{tabular}




\begin{tabular}{|c|c|c|c|c|}
\hline Variables & Mean & $\begin{array}{c}\text { Standard } \\
\text { Deviation }\end{array}$ & $\begin{array}{c}\text { Group } \\
\text { Cognitive } \\
\text { Complexity }\end{array}$ & $\begin{array}{c}\text { Satisfaction } \\
\text { Scale }\end{array}$ \\
\hline${ }^{\mathrm{A}}$ Internal consistency reliabilities are presented on the diagonal. \\
${ }^{*} p<.10$
\end{tabular}

Table 2. Means, Standard Deviations, and Sample Sizes by Condition

\begin{tabular}{|c|c|c|c|c|c|c|c|c|}
\hline \multirow[b]{3}{*}{ Variables } & \multicolumn{4}{|c|}{ High Cognitive Complexity } & \multicolumn{4}{|c|}{ Low Cognitive Complexity } \\
\hline & \multicolumn{2}{|c|}{$\begin{array}{l}\text { High Task } \\
\text { Complexity }\end{array}$} & \multicolumn{2}{|c|}{$\begin{array}{l}\text { Low Task } \\
\text { Complexity }\end{array}$} & \multicolumn{2}{|c|}{$\begin{array}{l}\text { High Task } \\
\text { Complexity }\end{array}$} & \multicolumn{2}{|c|}{$\begin{array}{l}\text { Low Task } \\
\text { Complexity }\end{array}$} \\
\hline & Centralized & Decentralized & Centralized & Decentralized & Centralized & Decentralized & Centralized & Decentralized \\
\hline $\begin{array}{l}\text { Satisfaction } \\
\text { Scale }\end{array}$ & $\begin{array}{l}20.8 \\
(2.2) \\
n=13\end{array}$ & $\begin{array}{l}20.6 \\
(2.5) \\
\mathrm{n}=11\end{array}$ & $\begin{array}{l}21.1 \\
(1.7) \\
n=10\end{array}$ & $\begin{array}{l}20.0 \\
(3.6) \\
n=9\end{array}$ & $\begin{array}{l}19.4 \\
(2.3) \\
n=9\end{array}$ & $\begin{array}{l}23.3 \\
(1.9) \\
n=9\end{array}$ & $\begin{array}{l}20.1 \\
(2.5) \\
n=7\end{array}$ & $\begin{array}{l}18.5 \\
(2.9) \\
n=7\end{array}$ \\
\hline
\end{tabular}

\section{Manipulation Checks}

Student t-tests were used to check for the strength of the manipulations of task complexity and group structure. To identify whether subjects perceived a difference in the two types of tasks (simple and complex), subjects were asked to indicate their perception of task complexity on a five-point scale $(1=$ simple; $5=$ complex $)$. A significant difference between the two conditions was obtained in the expected direction, $t(1,74)=-2.34, p<.01$. Subjects in the simple task condition rated the task as significantly less complex.

A second questionnaire measured the perceived level of structure in the group (centralized versus decentralized). Five separate items rated on a 5-point scale $(1=$ definitely true $5=$ definitely false) were asked of respondents. These ratings were summed as a measure of group structure (Cronbach alpha $=.76$ ). Sample questions measuring group structure include: "Members of the group worked under close supervision," and "A member had to think twice before speaking in the group's meeting." A significant difference between centralized and decentralized groups was obtained thus providing support for the effectiveness of the group structure manipulation, $t(1,74)=2.92, p<.001$.

\section{Tests of Hypotheses}


The analysis of the data was designed to answer whether there were differences in the measures of satisfaction across groups with different levels of group cognitive complexity, task complexity, and group structure. ANOVA was used to assess the effects of treatment conditions.

Hypothesis 1 proposed that group cognitive complexity and task complexity would interact to influence satisfaction. Specifically, higher cognitive complexity groups were expected to be most satisfied with a complex task, whereas, lower cognitive complexity groups were expected to be most satisfied with a simple task. As shown in Table 3, support was not found for Hypothesis $1, F(1,72)=2.43, p>.05$.

Table 3. ANOVA Results Showing the Influence of Group Cognitive Complexity, Task Complexity, and Group Structure on Satisfaction

\begin{tabular}{|l|c|c|}
\hline Dependent Variable - Satisfaction & df & F \\
\hline Group Cognitive Complexity & 1 & 0.26 \\
Task Complexity & 1 & 3.28 \\
Group Structure & 1 & 0.18 \\
\hline Group Cognitive Complexity X Task Complexity & 1 & 2.43 \\
Group Cognitive Complexity X Group Structure & 1 & 2.53 \\
Task Complexity X Group Structure & 1 & ${ }^{*} 7.51$ \\
Group Cognitive Complexity X Task Complexity X & 1 & ${ }^{*} 4.01$ \\
Group Structure & & \\
Model & 7 & ${ }^{*} 2.71$ \\
\hline
\end{tabular}

${ }^{*} p<.05 ;{ }^{* *} p<.01$

Hypothesis 2 proposed that group cognitive complexity and group structure would interact and influence satisfaction. Specifically, higher cognitive complexity groups were expected to rate a decentralized structure more highly than lower cognitive complexity groups. As shown in Table 3, support was not found for Hypothesis 2, $F(1$, $72)=2.53, p>.05)$.

Hypothesis 3 proposed that task complexity and group structure would interact and influence satisfaction. Specifically, groups performing a complex task were expected to rate the decentralized structure more highly than groups performing a simple task. As shown in Table 3, a significant interaction between task complexity and group structure was obtained, $F(1,72)=7.5 ; p<.01$, providing support for Hypothesis 3 . 
There were no significant main effects of task complexity or group structure on satisfaction; however, the main effect of task complexity approached significance, $p<.10$. Consequently, differences in task complexity at both levels of group structure were examined in a simple effects analysis. As shown in Table 4, scores on the satisfaction scale were significantly different between high and low levels of task when the structure was decentralized, $F(1,75)=7.82, p<.01$, but not when the structure was centralized, $F(1,75)=.41, p<.53$. The interaction is depicted in Figure 1 .

Table 4. Simple Effects Analyses Showing the Influence of Group Structure, Task Complexity, and Group Cognitive Complexity on Satisfaction

\begin{tabular}{|l|c|c|}
\hline $\begin{array}{l}\text { Hypothesis 2 - Group Structure X Task } \\
\text { Complexity }\end{array}$ & df & F \\
\hline \multicolumn{1}{|c|}{ Group Structure } & 1 & 0.05 \\
\hline Task Complexity & 1 & 2.50 \\
\hline Task Complexity within Centralized Structure & 1 & 0.41 \\
\hline Task Complexity within Decentralized Structure & 1 & $* * 7.82$ \\
\hline $\begin{array}{l}\text { Hypothesis 4 - Group Cognitive Complexity X } \\
\text { Group Structure X Task Complexity }\end{array}$ & & \\
\hline & $\mathbf{d f}$ & $\mathbf{F}$ \\
\hline Task Complexity & 1 & 3.28 \\
\hline Group Structure & 1 & 0.18 \\
\hline Task Complexity within Group Structure & 1 & $* * 7.51$ \\
\hline $\begin{array}{l}\text { Group CC within Simple Task } \\
\text { within Centralized Structure }\end{array}$ & 1 & 0.62 \\
\hline $\begin{array}{l}\text { Group CC within Simple Task } \\
\text { within Decentralized Structure }\end{array}$ & 1 & 1.32 \\
\hline $\begin{array}{l}\text { Group CC within Complex Task } \\
\text { within Centralized Structure }\end{array}$ & 1 & 2.00 \\
\hline $\begin{array}{l}\text { Group CC within Complex Task } \\
\text { Within Decentralized Structure }\end{array}$ & 1 & $* * 5.85$ \\
\hline p<.05; ** $p<.01$ & & \\
\hline
\end{tabular}


Figure 1. The Interaction Effect of Task Complexity and Group Structure on Satisfaction

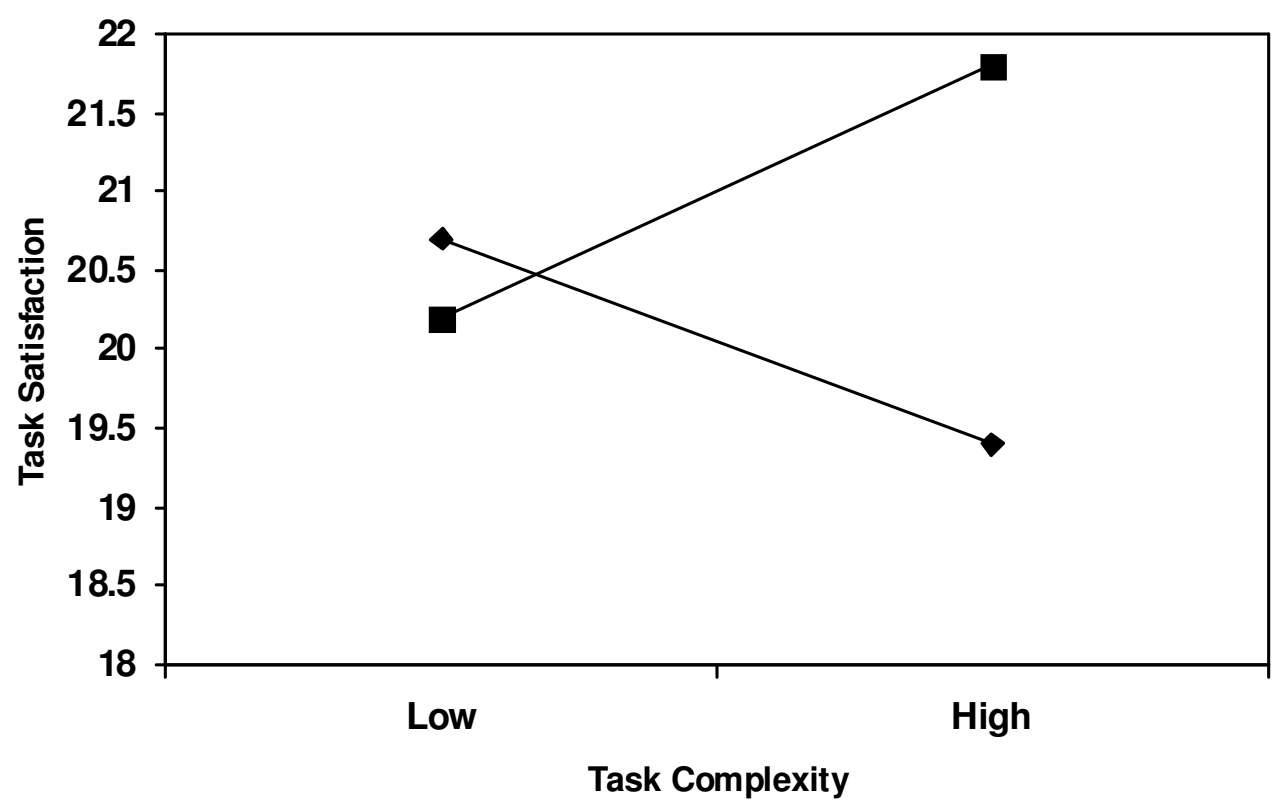

\section{$\multimap-$ Centralized $\rightarrow-$ Decentralized}

Hypothesis 4 proposed that group cognitive complexity, task complexity, and group structure would interact and influence satisfaction. Specifically, groups with higher cognitive complexity were expected to rate high satisfaction in a complex task and decentralized structure, whereas lower cognitive complexity groups were expected to rate high satisfaction in a simple task and centralized structure. As shown in Table 3, group cognitive complexity, task complexity and group structure did jointly influence group satisfaction, $F(1,72)=4.0, p<.05)$.

Figure 2. The Interaction Effect of Task Complexity, Group Cognitive Complexity, and Group Structure on Satisfaction 


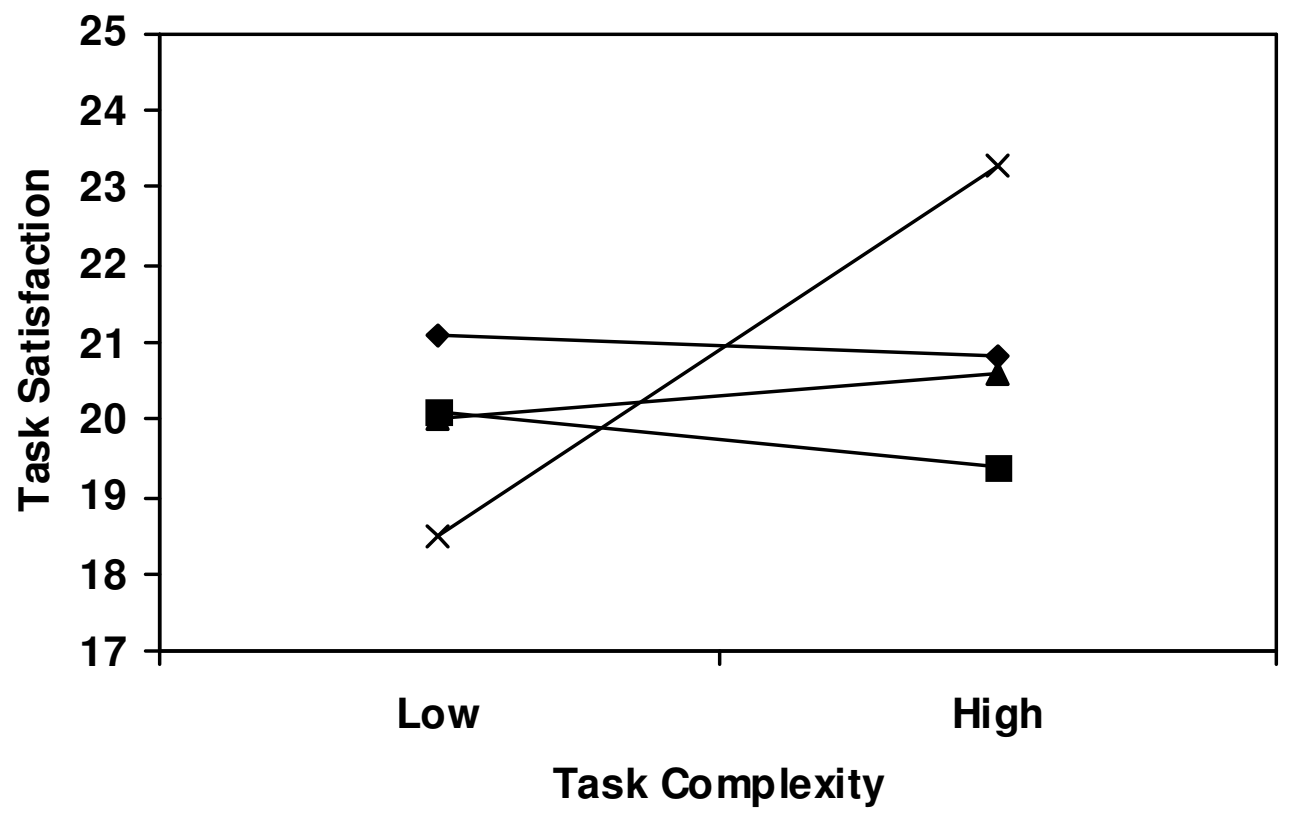

$\rightarrow-$ High Cognitive Complexity - Centralized Group Structure
$\rightarrow-$ Low Cognitive Complexity - Centralized Group Structure
$\rightarrow-$ High Cognitive Complexity - Decentralized Group Structure
$\rightarrow-$ Low Cognitive Complexity - Decentralized Group Structure

An analysis of simple effects for differences in satisfaction between high and low cognitive complexity groups was done for the interaction of task complexity by group structure. Results indicate a significant difference in satisfaction between groups when the task was complex and the structure was decentralized, $F(1,68)=5.85, p<.01$ ). Figure 2 graphically depicts the significant three-way interaction. When the task was complex and the group had a decentralized structure, groups with low cognitive complexity had higher task satisfaction than when the task was noncomplex. This finding suggests that groups lower in cognitive complexity were more highly influenced than complex groups by a mismatch between task complexity and group structure (i.e., simple task with a decentralized group structure or complex task with a centralized group structure). That is, when a complex task was performed in a decentralized structure, groups with low cognitive complexity were significantly more satisfied than when a less complex task was performed in a decentralized structure. Consequently, although a significant, three-way interaction was obtained, these results are not as predicted.

\section{Discussion}


The relationships of group cognitive complexity, task complexity, and group structure with satisfaction were analyzed in this study, bringing together both cognitive and group research. The significant relationships found in this study provide information on the outcomes associated with group cognitive complexity, although results were not always in the predicted direction.

Hypothesis 1 specifically predicted that the interaction between group cognitive complexity and task complexity would influence satisfaction. No support was obtained for this relationship. As shown through the manipulation checks, the task complexity manipulation was successful; however, the complex version of the Winter Survival Exercise may not have provided high cognitive complexity groups with the optimal level of activation. The same could be said about low cognitive complexity groups working on less complex tasks. If the match between group cognitive complexity and task complexity was not optimal, the predicted relationship may not have been detected.

The analysis did not support Hypothesis 2 which predicted that an interaction between group cognitive complexity and group structure would influence satisfaction. In general, all groups were more satisfied in the decentralized structure. Although manipulation checks revealed significant differences in group structure conditions, it is possible there was insufficient time for group members to develop rapport with the leader in the centralized condition, which could have impacted their satisfaction level. Furthermore, the short time period of the experiment may not have been sufficient for observing different reactions to group structure on the basis of group cognitive complexity.

Hypothesis 3 predicted that the interaction between task complexity and group structure would influence satisfaction. The current study indicated that when the task was complex, a decentralized structure led to greater satisfaction than a centralized structure, thus supporting the hypothesis. Perhaps a free-flow of information allowed decentralized groups to handle more information in the complex task, leading to high satisfaction. Groups performing a less complex task were likely satisfied with a centralized structure because of the reduced need to exchange large amounts of information.

Analysis of Hypothesis 4 produced a significant three-way interaction effect of group cognitive complexity, task complexity, and group structure on satisfaction (see Figure 3 ). It was predicted that a high cognitive complexity group performing a complex task would be most satisfied with a decentralized structure, whereas a low cognitive complexity group performing a simple task would be most satisfied with a centralized structure. First, results indicated that regardless of the cognitive complexity of groups, all groups were more satisfied working on a complex task with a decentralized structure. In addition, a significant, three-way interaction was obtained, but not as predicted. Specifically, groups composed of low cognitive complexity members were 
significantly

Figure 3: Model Depicting the Interaction of Task Complexity, Group Structure, and Group Cognitive Complexity on Satisfaction

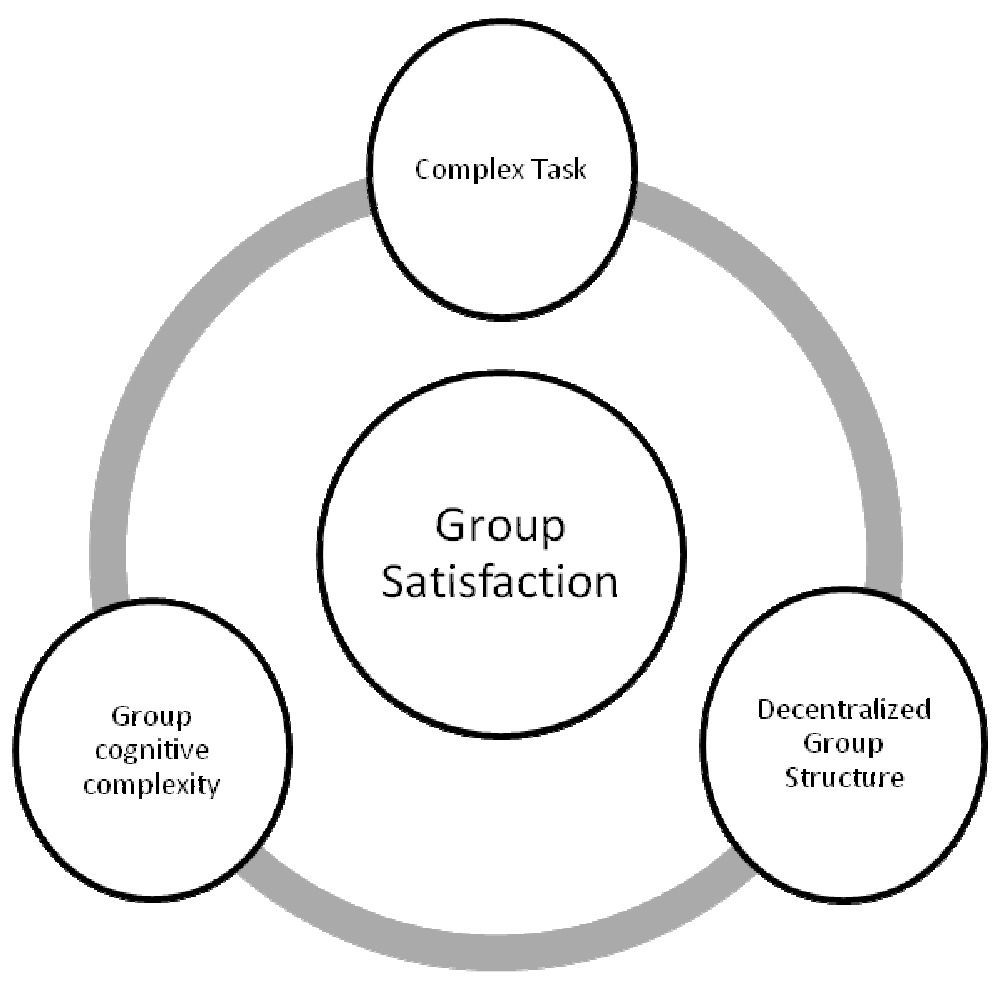

more satisfied with a complex task and a decentralized structure than were low cognitive complexity groups in a less complex task with a decentralized structure.

This result may be explained by the needs of low cognitive complexity groups (Suedfeld \& Streufert, 1966). Low cognitive complexity groups may not be able to adapt to situations where there is not enough information or participation when solving a complex problem. There is inherent complexity in the Winter Survival Exercise in that each of the items can be used in conjunction with the other items for survival purposes. It is possible that the task with fewer items may have caused low cognitive complexity groups difficulty in performing with suboptimal information. Furthermore, the centralized structure of their groups did not allow for much input from group members. Complex groups have been shown to have more tolerance of various group structures and levels of task complexity (Streufert, Streufert, \& Castore, 1968) and thus will have less variation in their satisfaction scores. Further research should help to uncover the explanation for these results and help to answer the following questions. Do low 
cognitive complexity groups actually prefer a complex task in a decentralized group structure? Or, is it their cognitive structure that does not allow them to adapt to the other combinations of task complexity and group structure?

\section{Implications}

An important issue related to the use of groups in organizations is how to structure groups to maximize satisfaction (Druckman \& Bjork, 1991). Results from the current study suggest implications for the improved use of groups in the work organization.

First, group cognitive complexity may help explain why certain groups are more satisfied than others. Attempts to improve the satisfaction of low cognitive complexity groups may require a focus on matching the complexities of the task to the structure of the group. The first step may be to assess group cognitive complexity. Those groups that are low in cognitive complexity may benefit from complexity training (Bartunek et. al., 1983). Incorporating the use of decision-making procedures such as dialectical inquiry, devil's advocacy, nominal group technique, and brainstorming may lead to higher levels of group complexity, providing for greater satisfaction across a wider range of tasks within varying levels of group structure.

Furthermore, it can be stressed that a decentralized group structure should not be viewed as the preferred management approach for all groups. This group structure should be congruent with the task complexity for low cognitive complexity groups. If there is a mismatch between group structure and task complexity, less cognitively complex groups may experience low satisfaction. Our results suggest that to improve satisfaction, managers may need to create challenging tasks in decentralized structures for all groups regardless of their complexity levels. When the task is not complex, the structure of the group may be less important for group satisfaction.

\section{Limitations and Future Research}

Although this research explored new relationships, there are limitations. First, the issue of external validity needs to be addressed. In assessing external validity, the subject population is a crucial factor. This laboratory study utilized novices to perform a task that was developed for the training of groups about the consequences of group decision-making. Although the performance of novice groups may be lower than that of groups with experience working together, the constructs of interest in our study are applicable to a variety of groups. A second limitation relates to the existing knowledge structures of the groups, which may have played a part in the accuracy of the decision in the Winter Survival Exercise. The life experiences, as well as the experience with this type of task, may have biased the results. Third, the short list of survival items may have contained a combination of items that were relatively easier (or harder) to prioritize than the full list, thus impacting the complexity of the task. 
An imperative requirement for future research is to establish the construct validity of group cognitive complexity. This would include developing a model of the antecedents, potential moderators, and outcomes of group cognitive complexity. Also, to further understand the relationship between satisfaction and group cognitive complexity, the current study could be replicated in a business setting using existing groups with varying levels of cognitive complexity.

\section{References}

Ashforth, B. E., \& Fried, Y. (1988). The mindlessness of organizational behaviors. Human Relations, 41, 305-329.

Bartel, C. A., \& Saavedra, R. (2000). The collective construction of work group moods. Administrative Science Quarterly, 45(2), 197-231.

Bartunek, J. M., Gordon, J. R., \& Weathersby, R. P. (1983). Developing "complicated" understanding in administrators. Academy of Management Review, 8(2), 273284.

Berlyne, D. E. (1960). Conflict, arousal, and curiosity. New York, NY: McGraw-Hill.

Bieri, J. (1956). Cognitive complexity-simplicity and predictive behavior. Journal of Abnormal and Social Psychology, 51, 263-268.

Bieri, J. (1961). Complexity-simplicity as a personality variable in cognitive and preferential behavior. In D. W. Fiske \& S. R Maddi (Eds.), Functions of varied experience (pp. 335 - 379). Homewood, IL: Dorsey.

Blaylock, B. K., \& Rees, L. P. (1984). Cognitive style and the usefulness of information. Decision Sciences, 15(1), 74-91.

Borsig, C. A., \& Frey, D. (1979). Satisfaction with group process and group decision as a function of group structure. Psychological Reports, 44, 699-705.

Bower, C. A., Pharmer, J. A., \& Salas, E. (2000). When member homogeneity is needed in work teams: A meta-analysis. Small Group Research, 31(3), 305-327.

Bottger, P. C., \& Yetton, P. W. (1987). Improving group performance by training in individual problem solving. Journal of Applied Psychology, 72(4), 651-657.

Brown, T. M., \& Miller, C. E. (2000). Communication networks in task-performing groups: Effects of task complexity, time pressure, and interpersonal dominance. Small Group Research, 31(2), 131-157.

Campbell, D. T. (1974). Evolutionary epistemology in the philosophy of Karl Popper. In P. A. Schilpp (Ed.), Vol. 14 (pp. 413-463). Lasalle, IL: Open Court Publishing.

Campbell, J. D., \& Gingrich, K. (1986). The interactive effects of task complexity and participation on task performance: A field experiment. Organizational Behavior and Human Decision Processes, 38(2), 162-180.

Campion, M. A., Medseker, G. J., \& Higgs, A. C. (1993). Relations between work group characteristics and effectiveness: Implications for designing effective work groups. Personnel Psychology, 46, 823-850.

Carroll, T., \& Burton, R. M. (2000). Organizations and complexity: Searching for the 
edge of chaos. Computational \& Mathematical Organization Theory, 6(4), 319337.

Cheng, S., \& Chang, H. (2009). Performance implications of cognitive complexity: An empirical study of cognitive strategic groups in semiconductor industry. Journal of Business Research, 62(12), 1311-1320.

Cohen, J., \& Cohen, P. (1983). Applied multiple regression/correlation analysis for the behavioral sciences $\left(2^{\text {nd }}\right.$ ed.). Hillsdale, NJ: Erlbaum.

Cooke, N. J., Kiekel, P. A., Salas, E., Stout, R., Bowers, C., \& Cannon-Bowers, J. (2003). Measuring team knowledge: A window to the cognitive underpinnings of team performance. Group Dynamics, 7(3), 179-199.

Cooke, N. J., Salas, E., Cannon-Bowers, J. A., \& Stout, R. J. (2000). Measuring team knowledge. Human Factors, 42, 151-173.

Cooke, N. J., Salas, E., Kiekel, P. A., \& Bell, B. (2004). Advances in measuring team cognition. In E. Salas \& S. M. Fiore (Eds.), Team cognition: Understanding the factors that drive process and performance. Washington, DC: American Psychological Association.

Cummings, L. L., Huber, G. P., \& Arendt, E. (1974). Effects of size and spatial arrangements on group decision making. Academy of Management Journal, 17(3), 460-475.

Curseu, P. L., \& Rus, D. (2005). The cognitive complexity of groups: A critical look at team cognition research. Cognitie, Creier, Comportament (Cognition, Brain, Behavior), 9(4), 681-710.

Curseu, P. L., Schruijer, S., \& Boros, S. (2007). The effects of groups' variety and disparity on groups' cognitive complexity. Group Dynamics: Theory Research, and Practice, 11(3), 187-206.

Day, H. L. (1966). Looking time as a function of stimulus variables and individual differences. Perceptual and Motor Skills, 22, 423-428.

Day, H. L. (1967). Anxiety, curiosity, and arousal. Ontario Psychological Association Quarterly, 20, 11-17.

Day, H. L. (1968). The importance of symmetry and complexity in the evaluation of complexity interest, and pleasingness. Psychonomic Science, 10(9), 339-340.

DeLuca, J., \& Stumpf, S. (1981). Problem solving and decision making: A proposed differentiation. Paper presented at the meeting of the Academy of Management, San Diego, CA.

Devine, D. J. (2002). A review and integration of classification systems relevant to teams in organizations. Group Dynamics, 6(4), 291-310.

Druckman, D., \& Bjork, R. A. (Eds.). (1991). In the mind's eye: Enhancing human performance. Washington, DC: National Academy Press.

Duncan, R. (1973). Multiple decision making structure in adapting to environmental uncertainty. Human Relations, 26(3), 273-291.

Dunn, W. N., \& Ginsberg, A. (1986). A sociocognitive network approach to organizational analysis. Human Relations, 40(11), 955-976.

Fisher, C. D. (1987). Boredom: Construct, causes, and consequences. Technical 
Report ONR-9. A\&M University, TX.

Fiske, D. W., \& Maddi, S. R. (1961). Functions of varied experience. Homewood, IL: Dorsey Press.

Fiske, S., \& Taylor, S. (1984). Social cognition. Reading, MA : Addison-Wesley. Galbraith, J. R. (1969). Organization design: An information processing view. Working paper \#425-469. Cambridge: Massachusetts Institute of Technology, Sloan School of Management.

Galbraith, J. R. (1977). Organizational design. Reading, MA: Addison-Wesley.

Gardner, D. G. (1986). Activation theory and task design: An empirical test of several new predictions. Journal of Applied Psychology, 71(3), 411-418.

Gardner, D. G., \& Cummings, L. L. (1988). Activation theory and job design: Review and reconceptualization. In B. Staw \& L. L. Cummings (Eds.) Research in organizational behavior (Vol. 10, pp. 81-122). Greenwich, CT: JAI Press Inc.

Ginsberg, A. (1990). Connecting diversification to performance: A sociocognitive approach. Academy of Management Review, 15(3), 514-535.

Gladstein, D. L. (1984). Groups in context: A model of task group effectiveness: A test of a contingency model. Academy of Management Journal, 27, 221-246.

Goodwin, V. L., Wofford, J. C., \& Harrison, D. (1990). Measuring cognitive complexity in the organizational domain. Paper presented at the annual meeting of the Academy of Management. San Francisco, CA.

Goodwin, V. L., \& Ziegler, L. (1998). A test of relationships in a model of organizational cognitive complexity. Journal of Organizational Behavior, 19, 371-387.

Greenberg, J., \& Folger, R. (1983). Procedural justice, participation, and the fair process effect in groups and organizations. In P. B. Paulus (Ed.), Basic group processes (pp. 235-256). New York: Springer-Verlag.

Hackman, J. R. (1987). The design of work teams. In J. W. Lorsch (Ed.), Handbook of organized behavior (pp. 172-189). Englewood Cliffs, NJ: Prentice Hall.

Hoffman, B.J., \& Woehr, D. J. (2006). A quantitative review of the relationship between person-organization fit and behavioral outcomes. Journal of Vocational Behavior, 68(3), 389-399.

Hodgkinson, G. P. (2002). Comparing managers' mental models of competition: Why self-report measures of belief similarity won't do. Organizational Studies, 23(1), 63-72.

Huber, G. (1985). Temporal stability and response-order biases in participant descriptions of organizational decisions. Academy of Management Journal, 28(4), 943-950.

Johnson, D. W., \& Johnson, F. P. (1994). Joining together: Group theory and group skills. Boston: Allyn and Bacon.

Jones, A. (1964). Drive and incentive properties associated with the statistical properties of sequences of stimuli. Journal of Experimental Psychology, 67(5), 423-431.

Katzell, R. A., \& Guzzo, R. A. (1983). Psychological approaches to productivity improvement. American Psychologist, 38(4), 468-472. 
Kelly, G. A. (1955). The psychology of personal constructs. Volume 1: A theory of personality. New York: W. W. Norton.

Kristof-Brown, A. L, Zimmerman, R. D., \& Johnson, E. C. (2005). Consequence of individuals' fit at work: A meta-analysis of person-job, person-organization, person-group, and person-supervisor fit. Personnel Psychology, 58, 281-342.

Lagan-Fox, J., Code, S., \& Langfield-Smith, K. (2000). Team mental models:

Techniques, methods, and analytic approaches. Human Factors, 42(2), 242-271.

Lord, R. G., \& Foti, R. J. (1986). Schema theories, information processing, and organization behavior. In H. P. Sims Jr., D. A. Gioia, and Associates (Eds.), The thinking organization (pp. 20-48). San Francisco: Jossey-Bass.

Lord, R. G., \& Kernan, M. C. (1987). Scripts as determinants of purposeful behavior in organizations. Academy of Management Review, 12(2), 256-277.

Louis, M. R., \& Sutton, R. J. (1991). Switching cognitive gears: From habits of mind to active thinking. Human Relations, 44(1), 55-76.

Manz, C. C. (1992). Mastering self-leadership: Empowering yourself for personal excellence. Englewood Cliffs, New Jersey: Prentice Hall.

Manz, C. C., Mossholder, K., \& Luthans, F. (1987). An integrated perspective of selfcontrol in organizations. Administration and Society, 19(1), 3-24.

March, J., \& Simon, H. (1958). Organizations. New York: Wiley.

Mason, C. M., \& Griffin, M. A. (2002). Grouptask satisfaction: Applying the construct of job satisfaction to groups. Small Group Research, 33(3), 271-312.

Mason, C. M., \& Griffin, M. A. (2003). Identifying Group Task Satisfaction at Work. Small Group Research, 34(4), 413-442.

Mohammend, S., Klimoski, R., \& Rentsch, J. R. (2000). The measurement of team mental models: We have no shared schema. Organizational Research Methods, 3(2), 123-165.

McGrath, J. (1984). Group: Interaction and Performance. Englewood Cliffs, NJ: Prentice-Hall.

McNamara, G. M., Luce, R. A., Tompson, G. H. (2002). Examining the effect of complexity in strategic group knowledge structures on firm performance. Strategic Management Journal, 23(2), 153-170.

Miller, K. I., \& Monge, P. E. (1986). Participation, satisfaction, and productivity: A metaanalytic review. Academy of Management Journal, 29(4), 727-753.

Minton, H. L. (1963). A replication of perceptual curiosity as a function of stimulus complexity. Journal of Experimental Psychology, 66(5), 522-524.

Neill, S, \& Rose, G. M. (2006). The effect of cognitive complexity on marketing strategy and organizational performance. Journal of Business Research, 59(1), 1-10.

Park, H. S., Baker, C., \& Lee, D. W. (2008). Need for cognition, task complexity, and job satisfaction. Journal of Management in Engineering, 24(2), 111-117.

Pennings, J. (1975). The relevance of the structural-contingency model for organizational effectiveness. Administrative Science Quarterly, 20(3), 393-410.

Rose, A. J., Mason, R. O., \& Dicken, K. E. (1987). Strategic management: A methodological approach. Reading, MA: Addison-Wesley. 
Schroder, H. M., \& Suedfeld, P. (1971). Personality theory and information processing. New York: Ronald Press.

Schroder, H. M., Driver, M., \& Streufert, S. (1967). Human information processing. New York: Holt, Rinehart and Winston.

Schruijer, S. G. L., \& Vansina, L. (1997). An introduction to group diversity. European Journal of Work and Organizational Psychology, 6(2), 129-138.

Scott, W. E., Jr., \& Erskine, J. A. (1980). The effects of variations in task design and monetary reinforcers on task behavior. Organizational Behavior and Human Performance, 25, 311-335.

Scott, W. E., Jr. (1966). Activation theory and task design. Organizational Behavior and Human Performance, 1(1), 3-30.

Shaw, M. (1954). Some effects of unequal distribution of information upon group performance in various communication nets. Journal of Abnormal and Social Psychology, 49(4), 547-553.

Shaw, M. (1964). Communication Networks. In L. Berkowitz (Ed.), Advances in experimental social psychology, New York: Academic Press.

Simonson, E., \& Weiser, P. C. (1976). Psychological aspects and physiological correlates of work and fatigue. Springfield, IL: Charles C. Thomas.

Spokane, A. R. (1996). Holland's theory. In D. Brown \& L. Brooks (Eds.), Career choice and development (3rd ed., pp. 33-74), San Francisco: Jossey-Bass.

Stone, E.F. (1977). Some personality correlates of perceptions of and reactions to task characteristics. Institute for Research in the Behavioral, Economic, and Management Sciences, Purdue University, Paper No. 594.

Streufert, S. (1984). The dilemma of excellence: How strategic decision-making can kill you. International Management, 39, 36-40.

Streufert, S., Clardy, M. A., Driver, M. J., Karlins, M, Schroder, H. M., \& Suedfeld, P. (1965). A tactical game for the analysis of complex decision making in individuals and groups. Psychological Reports, 17, 723-729.

Streufert, S., Kliger, S. C., Castore, C. H., \& Driver, M. J. (1967). Tactical and negotiations game for analysis of decision integration across decision areas. Psychological Reports, 20, 155-157.

Streufert, S., Pogashi, R., \& Piasecki, M. (1988). Simulation-based assessment of managerial competence: Reliability and validity. Personnel Psychology, 41, 537557.

Streufert, S., \& Streufert, S. (1978). Behavior in complex environment. New York: Wiley.

Streufert, S., Streufert, S. C., \& Castore, C. H. (1968). Leadership in negotiations and the complexity of conceptual structure. Journal of Applied Psychology, 52(3), 218-223.

Streufert, S., Swezey, R. W. (1986). Complexity, managers, and organizations. Orlando FL: Academic Press Inc.

Suedfeld, P., \& Streufert, S. (1966). Information search as a function of conceptual and environmental complexity. Psychonomic Science, 4, 351-352. 
Tinsley, H. E. A. (2000). The congruence myth: An analysis of the efficacy of the person-environment fit model. Journal of Vocational Behavior, 56(2), 147-179.

Triandis, H. (1977). Interpersonal behavior. Monterey, CA: Brooks/Cole.

Tripodi, T., \& Bieri, J. (1964). Information transmission in clinical judgments as a function of stimulus dimensionality and cognitive complexity. Journal of Personality, 32, 119-137.

Vannoy, J. S. (1965). Generality of cognitive complexity-simplicity as a personality construct. Journal of Personality and Social Psychology, 2(3), 385-396.

Vogel, R. M., \& Feldman, D. C. (2009). Integrating the levels of person-environment fit: The roles of vocational fit and group fit. Journal of Vocational Behavior, 75(1), 68-81.

Wall Jr., V. D., \& Nolan, L. L. (1987). Small group conflict: A look at equity, satisfaction, and styles of conflict management. Small Group Behavior, 18, 188-211.

Walsh, J. P., Henderson, C. M., \& Deighton, J. (1988). Negotiated belief structures and decision performance: An empirical investigation. Organizational Behavior and Human Decision Processes, 42, 194-216.

Weber, S. S., \& Donahue, L. M. (2001). Impact of highly and less job-related diversity on work group cohesion and performance: A meta-analysis. Journal of Management, 27(2), 141-162.

Weick, K. E., \& Roberts, K. H. (1993). Collective mind in organizations: Heedful interrelating on flight decks. Administrative Science Quarterly, 38, 357-381

Wood, R. (1986). Task complexity: Definition of the construct. Organizational Behavior and Human Decision Processes, 37(1), 60-82. 